\title{
THE EFFECT OF BRAND CLASS ON PERCEIVED FAIRNESS OF REVENUE
} MANAGEMENT

\author{
Wayne Taylor \\ Venetian Resort Hotel Casino \\ Las Vegas, NV 89109 \\ wayne.j.taylor@gmail.com
}

\author{
Sheryl E. Kimes \\ Cornell University \\ School of Hotel Administration \\ 243 Statler Hall \\ Ithaca, New York 14853 \\ Sek6@cornell.edu
}

\begin{abstract}
The purpose of this survey-based research was to determine whether brand class influences the perceived fairness of hotel revenue management (RM) pricing strategies. We found that brand class does not impact perceptions of fairness of RM pricing practice strategies when controlling for familiarity and the provision of information. The implication is that managers should not base RM pricing practice decisions on brand class, but rather should focus on raising customer familiarity of their pricing strategies.
\end{abstract}

KEYWORDS: pricing; revenue management; hotels; perceived fairness; brand class; familiarity 


\section{INTRODUCTION}

Hotels use pricing and duration controls (that is, a minimum or maximum length of stay restriction) to manage demand and maximize revenue. Although earlier hotel revenue management (RM) approaches relied heavily on duration controls, pricing strategies have grown in importance. When hotels implement pricing strategies, customers are charged different prices for using the same service, depending on customer and demand characteristics. To justify these rate differences, hotels rely on rate fences. Rate fences segment the customers based on willingness to pay and can be based on day of week, amount of time a room is booked before arrival, time of year, room location, or any other variable that will create distinct customer segments.

Given the importance of RM pricing in the hospitality industry today, it is important to understand what influences the perceptions of fairness of this pricing tactic. Perceived fairness has been shown to affect customer intent to return and profitability, and customers who believe that a company is behaving in an unfair fashion are less likely to patronize that firm in the future (Kahneman et al , 1986a; Campbell, 1999). Perceived fairness has been found to be affected by customer familiarity with RM pricing practices and the amount of information provided to the customer about the practice.

Luxury hotels may be hesitant to implement RM pricing strategies for fear of diminishing their appeal to customers (Burnsed, 2009; Volcheff, 2009). Alternatively, budget hotels may worry about offending price sensitive guests through the use of differential pricing. Previous research has examined variables that affect perceived fairness, but no research to our knowledge has examined how brand class may influence this perception. The purpose of this report was to examine if the perceived fairness of RM pricing strategies varies by brand class. 
First, we will review previous work relating to the purpose of this study. We next present our model that integrates brand class, familiarity and the provision of information to determine how brand class affects perceptions of fairness. We will then analyze the results of the model and discuss the managerial implications of the findings. Finally, opportunities for further research and the limitations of this study will be explored.

\section{LITERATURE REVIEW}

Although earlier hotel RM practices primarily relied on duration control strategies, pricing strategies have grown in importance (Kimes and Chase, 1998). When firms use differential pricing, customers are charged different prices for using the same service at the same time depending on customer and demand characteristics (Kimes and Chase, 1998). Companies must ensure that their price mix is logical, and use conditions (referred to as rate fences) to segment their customers based on willingness to pay (Kimes and Chase, 1998). For example, a customer who books a room many months out might be given a lower rate than a customer who books the day before arrival. Hotels use a variety of rate fences and include both physical rate fences (for example, different rates based on room location or amenities) and non-physical rate fences (for example, time of booking, length of stay restrictions). Although pricing strategies can lead to an increase in revenue, companies must ensure that customers perceive these practices as fair, as fairness perceptions will affect long-term firm profitability (Kahneman et al , 1986a).

Perceived fairness is paramount to long-term revenue maximization. We will first discuss perceived fairness and its importance to pricing strategies. Then, we will review how familiarity and the provision of information influence perceived fairness of RM. Finally, we will investigate how brand class affects the role of fairness perceptions. 


\section{Price changes and perceived fairness}

Customers who believe that a company is behaving in an unfair fashion are less likely to return to that company (Kahneman et al , 1986a), so it is important to understand the drivers of perceived fairness. In addition, perceived fairness affects customer satisfaction (Oliver and Swan, 1989; Sinha and Batra, 1999) and has been found to affect behavioral intentions (Campbell, 1999) and profitability.

Fairness perceptions are governed by the belief that firms are entitled to a reference profit, and customers are entitled to a reference price. Reference prices are the price that consumers feel is acceptable in the market. Price increases are considered to be fair if the increase does not result in an increased profit to the firm (Kahneman et al , 1986a). For example, in a hotel, increasing room rates without an equal increase in costs may be perceived as unfair.

Consumers appear willing to accept higher prices in return for increased quality. However, customers appear less willing to pay a higher price if a firm's strategy is to make profits through high margins rather than high volume (Bolton et al , 2003). Even if cost increases are beyond a firm's control, consumers are sometimes unwilling to accept necessary price increases (Bolton et al , 2003).

When customers perceive that the motive for a price increase is a fair one, customers have higher repurchase intentions (Homburg et al , 2005). Interestingly, customer satisfaction influences the perceived motives for the price increase; when customer satisfaction is high, positive motives are more likely to be inferred (Homburg et al , 2005).

\section{Familiarity}


Perceived fairness of pricing practices increases as consumers become more familiar with these practices (Wirtz and Kimes, 2007). Service exchanges that are initially seen as unfair may acquire the status of a reference transaction over time and provide a basis for fairness judgments because it is 'normal', but not necessarily reasonable (Kahneman et al , 1986a).

Consumers are affected by community norms of reference prices, and perceptions of fairness are judged relative to these norms (Kahneman et al ,1986a, 1986b). For example, customers have shifted their fairness perceptions towards RM applications in hotels over time. A study on the perceived fairness in the airline and hotel industry found that consumers viewed identical RM practices in the airline context fairer relative to the hotel context (Kimes, 1994). However, 8 years later a follow-up study found the fairness of both industries to be similar (Kimes and Noone, 2002). This suggests that as customers became more exposed to RM pricing their perceived fairness increases over time.

Customers who are familiar with RM pricing practices are less likely to be affected by fencing and framing (whether a price is presented as a discount or surcharge) conditions (Wirtz and Kimes, 2007). Familiar customers may be able to attribute different prices to services offered with different rate fences (for example, a hotel room booked far in advance is not the same as a hotel room booked the day before arrival, and therefore different prices are acceptable). In contrast, less familiar customers are more likely to make social comparisons on price (that is, 'I didn't receive the discount' or 'I received a surcharge') alone when evaluating the fairness of a pricing practice (Wirtz and Kimes, 2007).

\section{Role of information}


Perceived fairness is also affected by the type and amount of information given to consumers by the hotel. When a justification for a negative outcome is provided, the outcome is perceived as fairer than when no justification is offered. However, explanations perceived to demonstrate 'negative' (for example, insincere or manipulative) motives have been found to increase perceived unfairness (Greenberg and Ornstein, 1983). In addition, knowledge of how a price has been determined has a significant effect on perceived fairness (Maxwell, 2002).

If customers understand the reasoning behind a price change, then the procedure is more likely to be perceived as fair, but merely letting the customer know that hotel rates vary is not enough to improve customers' perceptions of fairness (Choi and Mattila, 2005). If respondents are given information on what affects the rate change (for example, day of week, length of stay, how far in advance the booking was made), their perceptions of fairness are likely to improve (Choi and Mattila, 2005).

\section{Brand name and quality}

Brands have been shown to shape consumer behavior (Aaker and Keller, 1990; Keller, 1993; Aaker, 1996). Consumers judge quality based on both external and intrinsic cues, and brand name has been shown to be the most important driver of choice (Dodds and Monroe, 1985; Dodds et al , 1991; Dawar and Parker, 1994). Extrinsic cues are typically product or servicebased and consist of things such as price, brand and packaging, whereas intrinsic price cues are things that are integral to the nature of the product or service (Rao and Monroe, 1988). Less familiar customers are more likely to use extrinsic cues as an indicator of quality, while more familiar customers are more likely to use intrinsic cues (Rao and Monroe, 1988; Dodds et al , 1991). 
Using brand names significantly increases perceived quality and willingness to buy (Dodds and Monroe, 1985). In addition, brand expectations have been found to be important predictors of purchase intentions and overall brand class expectations (Gupta and Stewart, 1996). Brand reputation and brand class are important variables that affect the customer value process. The reputation associated with a brand name is closely related to the perceived quality of the product or service (Shapiro, 1983; Zeithaml, 1988). High-quality brands have been found to have a higher price inelasticity in that increases in price are less likely to affect demand.

Although previous research has evaluated perceived price fairness, no published research has explicitly compared the perceived fairness of RM pricing strategies across brand classes. In addition, given that brand class is related to quality perceptions (Rao and Monroe, 1988; Dodds et al , 1991), we wanted to test how customers would react to discounting practices across brand class. Therefore, the purpose of this study was to determine how customers react to RM pricing strategies across brand classes.

\section{PROPOSED MODEL}

We developed a model that incorporates brand class as a predictor of perceived fairness of RM pricing practices (Figure 1). Previous research has addressed the impact of familiarity and the provision of information on perceived fairness (Choi and Mattila, 2005; Wirtz and Kimes, 2007). Our research builds on this while testing the impact of a new variable, brand class, on perceived fairness. In addition, the model accounts for the effects of brand class on information and familiarity.

[TABLE 1] 
Familiarity and information affect perceived fairness (Choi and Mattila, 2005; Wirtz and Kimes, 2007). This leads to the first two hypotheses:

Hypothesis 1: Consumers who are provided with additional information about a RM pricing practice will be more likely to perceive that the price is fair.

Hypothesis 2: Consumers who are more familiar with a RM pricing practice will view that practice as fairer than those who are less familiar.

Brand class has also been found to affect quality perceptions (Shapiro, 1983; Zeithaml, 1988). In addition, while price has been shown to signal quality, it has an inverse relationship with perceived value and perceived fairness (Kwun and Oh, 2004). Given that price has an inverse relationship with perceived fairness, RM pricing strategies may be perceived to be less fair at a higher brand class. This leads to the third hypothesis.

Hypothesis 3: Customers of higher-level brand classes will believe that RM pricing practices are less fair than customers of lower-level brand classes.

Brand class may have a significant interaction with information and familiarity (Choi and Mattila, 2005; Wirtz and Kimes, 2007). Familiarity and information have been shown to moderate the effect of various pricing strategies, regardless of whether the person receives an advantage from that strategy (Wirtz and Kimes, 2007). Based on this, customers provided with additional information and more familiar customers may find the perceived fairness of RM pricing to be the same regardless of brand class. 
This leads to the following two hypotheses:

Hypothesis 3a: Customers who are provided with additional information about RM pricing practices will consider the fairness of those practices to be the same, regardless of brand class.

Hypothesis 3b: Customers who are more familiar with RM pricing practices about pricing practices will consider the fairness of RM pricing practices to be the same, regardless of brand class.

Finally, perceived fairness has been shown to influence repurchase intentions (Campbell, 1999). This leads to the final hypothesis.

Hypothesis 4: Consumers who perceive a RM pricing practice to be fairer will have a higher intent to return.

\section{METHODOLOGY}

Measures for each of the model constructs were first developed and then administered to a nationwide survey. The survey was scenario-based; respondents read a paragraph describing a hotel stay and were then given questions related to the scenario. A scenario method was used to reduce potential problems introduced by personal circumstances to the research context (Havlena and Holbrook, 1986) and to reduce experimental noise by employing a standardized setting for all subjects (Cook and Campbell, 1979). Although not a perfect indicator of consumer behavior, the role-playing scenario approach has been used frequently in consumer behavior research (Kimes and Wirtz, 2003). 
The study was designed to create situations in which respondents were asked to compare their rate to those quoted to other customers. We chose this approach because expectation-based comparisons (when customers compare current rates to those quoted for previous stays) do not always result in perceptions of unfairness, regardless of whether the customer has received a favorable or unfavorable price (Choi and Mattila, 2005).

Three different factors were accounted for: type of trip (business versus leisure), level of information (information given or not) and hotel brand level (operationalized as five-star or three-star). This resulted in a $2 \times 2 \times 2$ design, for a total of eight unique scenarios. There were approximately 100 responses for each of the eight scenarios (see Appendix, Exhibit I).

The provision of information, familiarity and brand class are the primary variables in the proposed model. The variations in the provision of information across scenarios were adapted directly from previous research (Choi and Mattila, 2005). Statements on familiarity and experience with RM pricing strategies and frequency of hotel patronage were based on previous work (Wirtz and Kimes, 2007) and used a 7-level Likert scale.

Two other questions that measured acceptance of RM pricing policies were also included (adapted from Kimes and Wirtz (2003) and Kimes (1994)). Finally, the likelihood to return to the hotel and recommend it to others was also measured. All variables were measured on a 7-level Likert scale.

Perceived fairness was measured with four statements (adapted from Choi and Mattila (2005) and Wirtz and Kimes (2007)): (1) the hotel is behaving in a fair fashion; (2) the hotel took advantage of the customer; (3) I agree with the pricing policies of this hotel; and (4) I consider the outcome of this scenario to be acceptable. ${ }^{1}$ Respondent ratings for these four questions were then summed to form a Fairness Index. 
The survey was conducted in Fall 2008 and 815 completed responses were received. The respondents were quite representative of the US population by gender (48 per cent male, 52 per cent female) and by age (11 per cent, under 25 years; 27 per cent, 25-39 years; 30 per cent, 40-54 years; and 33 per cent, 55 years or above) (U.S. Census Bureau, 2007).

\section{Validating brand class through star level}

To determine whether respondents recognized the difference between the star levels within the scenarios, respondents were asked to indicate the level of service that they expected from the type of hotel that was given to them in the scenario. The five-star respondents rated the expected service level as 5.8 (with 7='High' and 1='Low') while the three-star respondents rated the expected service level at 5.0. There was a significant difference in the expected service levels between the three-star and five-star scenarios ( $P=0.000$ ), indicating that the respondents recognized the difference in the star levels in the scenarios.

\section{RESULTS}

We performed two sets of analyses. In the first set, we replicated previous research, so that we could see the impact of information, brand class and familiarity on perceived fairness. The second analysis was designed to control for other variables that may affect the perceptions of fairness.

We will first present the perceived fairness ratings associated with the three main components of the proposed model (information, familiarity and brand class) as well as their relationships to other variables. Then, we will present the perceived fairness ratings for type of trip (business versus leisure), frequency of hotel stays and demographic variables. 
Information : Information is a key determinant of perceived fairness (Choi and Mattila, 2005). Respondents who were given information about the reasons for price differences rated perceived fairness as significantly higher than those who were not given information (13.5 versus 12.6) ( $P$ $=0.035)$. Therefore, Hypothesis 1 is supported and validates previous research.

This result did not vary by age, gender or type of trip (business versus leisure). In addition, brand class did not have an effect on how information influences perceived fairness, which does not support Hypothesis 3a.

Familiarity : Familiarity with a RM pricing policy is a key determinant of perceived fairness (Kahneman et al , 1986a; Wirtz and Kimes, 2007). Perceived fairness was significantly higher for those who were familiar with RM pricing policies (15.9) than those who were not familiar (8.7) $(P=0.000)$. This supports Hypothesis 2 and validates previous research.

Perceived fairness varied by gender $(P=0.039)$ and star level $(P=0.045)$. More familiar male respondents felt that RM pricing practices were fairer than familiar female respondents (Male, 17.18; Female, 14.42). There were no significant differences in the perceived fairness of less familiar respondents (Male, 8.86; Female, 8.44). Similarly, less familiar respondents felt that RM pricing practices were the same for both three-star and five-star hotels (three-star, 8.55; fivestar, 8.75), but more familiar respondents believed that these practices were fairer at three-star hotels (three-star, 16.56; five-star, 15.24). This disproves Hypothesis 3b, which stated that brand class has no significant effect on perceived fairness for more familiar consumers. 
Although experience with a policy is not necessarily the same as familiarity with a policy, more experienced respondents had a significantly higher perceived fairness rating (15.8) than less experienced respondents (10.2) $(P=0.000)$. There were no significant interactions with other variables (age, gender, brand class, type of visit and information).

Star level : There was no significant difference between the perceived fairness ratings for threestar and five-star hotels $(P=0.298)$, which does not support Hypothesis 3 . Brand class does not appear to directly influence perceived fairness.

Type of trip : Leisure travelers appeared to be more accepting of RM pricing than business travelers. Leisure respondents had a significantly higher overall fairness rating (13.6 versus 12.6) $(P=0.020)$. There were no significant differences by age, gender, information or brand class.

Frequency : Perceived fairness increased with frequency of hotel stays $(P=0.000)$. The most infrequent group of respondents ('I've never stayed at this type of hotel') had a perceived fairness rating of 10.7 whereas the most frequent respondents (those who stay more than once per month) had a perceived fairness rating of 17.2.

There was a significant relationship between brand class and frequency level $(P=0.019)$. Infrequent hotel guests felt that the perceived fairness of RM pricing practices was about the same for both three-star and five-star hotels (11.97 and 11.67, respectively), whereas frequent hotel guests thought that such practices were fairer in five-star hotels (three-star, 15.71; five-star, 19.63). 
Demographics : The various demographics factors were examined to determine if perceived fairness differed significantly by age and gender. Men had significantly higher perceived fairness ratings (13.9) than women (12.3) ( $P=0.000)$, and younger respondents considered RM pricing practices to be fairer than older respondents $(P=0.015)$.

\section{Linking perceived fairness to return intentions}

Two questions ((1) How likely are you to recommend this hotel? and (2) How likely are you to return to this hotel?) were combined to develop a 'Return Index'. These two questions were grouped based on Cronbach's $\alpha(0.96)$.

In order to link perceived fairness to return intentions, a descriptive regression on the Fairness Index versus the Return Index was developed to test the strength of the relationship between changes in the Fairness Index and changes in the Return Index.

As expected, the relationship was significant $(P=0.000)$ and changes in the Fairness Index explained most of the changes in the Return Index ( $R$-squared of 0.67). This supports Hypothesis 4 and lends credence to the concept that understanding the drivers of perceived fairness will ultimately lead to understanding what makes customers return to the property.

\section{Hypotheses results of independent testing}

Overall, brand class has an effect on more familiar respondents but does not directly affect perceived fairness. In addition, perceptions of fairness influence return intentions. The results of the individual hypotheses tests are presented in Table 1).

\section{ANOVA results}


As the purpose of this study was to determine if there was a significant difference in perceived fairness based on brand class, an ANOVA model was built to test for these differences and to measure the effect of the three proposed constructs (brand class, familiarity and information).

Testing the variables in a single model (as opposed to testing the hypotheses individually) allows for the effects of each factor to be controlled by the presence of other factors. Testing in this manner is more comprehensive because the effects of the factors we are testing (brand class, familiarity and information) need to be understood simultaneously. Although each factor may show significant results in a single test on perceived fairness, the dynamics between the factors may change when presented together.

\section{[TABLE 2]}

First, a two-way ANOVA with Fairness Index as the dependent variable, and brand class, information and familiarity as the independent variables was developed (Table 2). Familiarity was the only significant factor ( $P=0.000)$, but the provision of information and the interaction between brand class and familiarity reached significance at the 0.10 level. The results of the ANOVA hypothesis tests are presented in Table 3.

\section{[TABLE 3]}

Information : Previous research has shown that the provision of information has a significant impact on the perceived fairness of RM pricing strategies. Perceived fairness was higher for 
respondents who were given information (13.5) than those who were not (12.6). While Hypothesis 1 was supported, this relationship was not significant when brand class and familiarity were controlled for.

Familiarity : Familiarity has been shown to affect the perceived fairness of RM pricing. More familiar respondents had a significantly higher perceived fairness rating (15.9) than unfamiliar respondents (13.5). Hypothesis 2 was also supported by the ANOVA model.

Familiarity $\times$ Information : Information had the same effect on perceived fairness for both familiar and unfamiliar respondents. Familiar respondents given information had similar perceived fairness ratings as those without information (information, 16.3; no information, 15.4). This was also true for unfamiliar respondents (information, 9.0; no information, 8.4).

Brand class : Consistent with the individual test of Hypothesis 3, brand class did not directly affect perceived fairness ratings. Respondents in the five-star scenario had a similar perceived fairness rating to those in the three-star scenario (five-star, 12.9; three-star, 13.3).

Consistent with Hypothesis 3a, brand class did not have a significant interaction with the provision of information $(P=0.458)$.

Respondents who were familiar with RM pricing had an average perceived fairness of 16.6 in the three-star scenarios and 15.2 in the five-star scenarios. In contrast, unfamiliar respondents showed no significant difference in perceived fairness (five-star, 8.8; three-star, 8.5). 
However, this interaction between brand class and familiarity was just marginally significant ( $P$ $=0.065)$.

\section{DISCUSSION}

Previous research has not yet accounted for the effects of brand class on the perceived fairness of RM pricing. In this study, we found that brand class does not significantly affect perceived fairness. Brand class had no significant impact as an individual variable nor did it influence the effects of familiarity or information.

We tested the effects of information, brand class and familiarity on the perceived fairness of RM pricing in both an isolated setting (that is, one variable at a time) and simultaneously through an ANOVA model. The purpose of testing in isolation was to support previous research and provide a foundation for our theory. No research to our knowledge has attempted to integrate the effects of familiarity and the provision of information on perceptions of fairness into a single model.

Information was a significant determinant of perceived fairness, but not when controlling for brand class and familiarity. Additionally, there was not a significant interaction with information. Previous research states that perceptions of fairness are likely to improve if respondents are given information on what affects rate change (Choi and Mattila, 2005), which is how the scenarios with information in this study were designed. As previous work has not controlled for other variables that may affect the perceptions of fairness, the results from the isolated test are consistent with previous work. However, after controlling for brand class and familiarity, the effect of information does not matter. This may be caused by respondents viewing variable pricing as an industry-wide practice that is not distinct to a brand class. In other 
words, regardless of whether a respondent was given information about the details of RM pricing (such as how prices are affected by day of week, amount of time before arrival and seasonality), the perceptions of the fairness of RM pricing were the same after accounting for brand class and their familiarity with RM pricing strategies.

The amount of information provided to customers has been tested for its effects on perceived fairness (Choi and Mattila, 2005), but research has yet to include familiarilty as a moderator on the provision of this information. Our study is consistent with previous findings in that we found there is a significant difference in perceived fairness when different levels of information are presented. However, in order to form a more comprehensive view of the customer we tested the effects of information while accounting for brand class and familiarity simultaneously. Testing in this manner allowed us to show that information is not as important if the level of familiarity with RM pricing is included.

Familiar respondents had significantly higher perceived fairness ratings. In addition, familiar customers had significantly higher perceived fairness ratings in the three-star scenarios than in the five-star scenarios, but this relationship was not significant when controlling for information and familiarity. Again, the respondents may be viewing RM pricing as an industrywide practice, thereby eliminating the effects of an individual brand class. Hotel customers may not be able to distinguish the pricing tactics between brand classes.

Still, familiarity by itself (without interacting with other variables) explains an overwhelming amount of variance in perceived fairness. As mentioned previously, service exchanges that are initially seen as unfair may acquire the status of a reference transaction over time and provide a basis for fairness judgments because it is 'normal', but not necessarily reasonable (Kahneman et al , 1986a). In this study, perceptions of fairness were influenced 
mostly by familiarity with the pricing policy. As customers become more familiar with RM pricing policies, they become more accepting of the practice. As mentioned above, information given to customers for a single transaction is not a significant determinant of perceived fairness, but giving information to customers on pricing policies may be one way to increase their familiarity with RM pricing policies.

\section{MANAGERIAL IMPLICATIONS}

This study examines the impact of hotel brand class on the perceptions of fairness of RM pricing policies strategies. We found that brand class does not significantly impact perceptions of fairness. In addition, brand class does not influence the effects of information and familiarity. Providing information to guests on factors that affect variable pricing does not significantly affect fairness perceptions after controlling for brand class and familiarity. Furthermore, this study validated previous research on familiarity by finding that more familiar guests will have significantly higher perceptions of fairness than unfamiliar guests. The managerial implications of these findings are discussed below.

Given that brand class does not affect perceptions of fairness, managers should not base RM pricing decisions on brand class. This includes avoiding the implementation of RM pricing because it will not 'fit' with the brand class of a hotel. In addition, creating different RM pricing rules based on brand class is not useful because consumers will most likely react similarly to RM pricing strategies across brand classes.

Although information is not a significant determinant of fairness perceptions, familiarity with RM pricing practices explains a significant amount of fairness perceptions. Given this, one way to raise familiarity with variable pricing is for managers to inform customers of the pricing 
policies. If customers seem upset or confused as to why different prices are charged, managers should inform them that the prices depend on how far out the room is booked, day of week, along with other variables that may affect pricing. Also, it is important for managers to tell the customer how prices change for each variable. For example, customers should understand that prices tend to be higher during the week and lower on the weekend, if this is the case.

In addition, managers should train employees to handle questions that customers may have about variable pricing. They should use standard operating procedures to ensure that customers receive a consistent message about differential pricing. Also, managers need to educate employees on the purpose and importance of RM pricing policies; this will allow them to handle customer questions more effectively.

Providing information to customers who ask about variable pricing will help raise familiarity, but this is a reactive solution. Managers should look to marketing as another, more proactive, medium to raise customer familiarity with RM pricing. Some marketing promotions should clearly indicate that prices are related to demand-based pricing. For example, promotions should focus on a season (for example, 'Summer Prices') or make it clear in other ways to customers that booking early will allow them to lock in lower rates. As always, managers need to ensure that these promotions are limited to the targeted market to ensure that customers who are willing will pay the standard rate. Marketing promotions provide another opportunity for the hotel to interact with their customers and raise their familiarity with RM pricing.

In conclusion, managers should not base RM pricing strategy decisions on brand class because it does not affect the perceived fairness of the pricing strategy, which is strongly related to return intentions. Managers should focus on raising customer familiarity with RM pricing through employees (for example, front desk and call center) and marketing efforts. Increasing 
familiarity is important because of its significant influence on perceptions of fairness, which in turn affects customer return intentions.

\section{LIMITATIONS AND FUTURE RESEARCH}

Understanding what influences perceptions of RM fairness is important because of the impact that perceived fairness has on hotel profitability. In this article, we explored the impact of brand class on these fairness perceptions and found that brand class does not have a significant impact on perceived fairness. The model showed a significant relationship between familiarity and perceptions of fairness, which is consistent with previous works.

While brand class itself is not a significant variable, research should continue to examine how brand class interacts with other variables. For example, the relationship between brand class and familiar customers may be different from the relationship between brand class and frequent customers. While this study focused on familiar customers, it is important to understand how frequent customers react to RM pricing by brand class. This idea needs to be explored further for managers to fully understand the implications.

In addition, the effects of information should be explored further. We are only aware of one paper that examines this relationship, and the model that we proposed found that information is not significant when accounting for brand class and familiarity. However, giving information may affect the perceptions of service level within a hotel. In other words, does providing information to customers augment or diminish the perceived service levels for hotels?

Given the strong relationship between perceptions of fairness and return intentions, it is important for researchers and managers to understand other variables that affect pricing fairness. The model presented in this article explained only a quarter of the variation in perceptions of 
fairness, implying that there may be other variables that are influencing the perception of fairness. Hotels are different in many ways, and understanding the impact on perceptions of fairness in each type of hotel should be analyzed to provide insight to managers. For example, do perceptions of fairness differ in hotels within casinos? Does the availability (level of competition) within an area affect perceptions of fairness?

In regards to the fairness of RM pricing, some of the open-ended responses from the survey participants indicated that they either thought that there should be one price for everyone or that prices should be determined by demand. Given that hotel customers still have such a broad view of RM pricing, future work should explore the effects of individual rate fences. For example, consumers may find that pricing by season (that is, summer versus winter) may be fair but pricing by day of week is not fair at all. A conjoint analysis could compare the strength of perceived fairness of a rate fence for booking early against a rate fence related to day of week pricing. Respondents could rate the fairness attributed to each current type of rate fence (for example, day of week pricing) in addition to rating the fairness of new types of rate fences (for example, pricing by time of day).

The primary limitation of this study is that consumer intentions are not the same as consumer behavior. Although scenario-based surveys work reasonably well to predict consumer behavior (Kimes and Wirtz, 2003), they are not perfect indicators. Until more accurate predictors of consumer behavior are discovered, it is likely that scenario-based surveys (in the absence of actual company data) will be used to approach problems similar to what was studied here. 


\section{CONCLUSION}

In this study we found that brand class does not affect perceptions of fairness or interact significantly with familiarity or information. The model that we have proposed reaffirms the importance of familiarity as it relates to perceptions of fairness, and has shown that giving information does not significantly impact perceptions of fairness when accounting for brand class and familiarity. The results from this study have important managerial implications for RM strategy, employee training and marketing. However, research is still far from complete in understanding what affects perceptions of price fairness in a RM context. 
Table 1. Summary of hypotheses tests.

\begin{tabular}{|c|c|c|}
\hline Hypothesis & Description & Result \\
\hline 1 & $\begin{array}{l}\text { Provision of information will increase the perceived } \\
\text { fairness of revenue management (RM) practices. }\end{array}$ & Supported \\
\hline 2 & $\begin{array}{l}\text { Consumers who are more familiar with a RM practice } \\
\text { will view that practice as more fair. }\end{array}$ & Supported \\
\hline 3 & $\begin{array}{l}\text { Customers of a higher-level brand class will believe that RM } \\
\text { practices are less fair than customers of lower-level brand classes. }\end{array}$ & Not Supported \\
\hline $3 a$ & $\begin{array}{l}\text { Customers who are provided with information about a } \\
\text { RM pricing practice will consider the fairness of those } \\
\text { practices to be the same, regardless of brand class. }\end{array}$ & Not Supported \\
\hline $3 b$ & $\begin{array}{l}\text { Customers who are more familiar with } \mathrm{RM} \text { pricing practices } \\
\text { will consider the fairness of these practices to be the same, } \\
\text { regardless of brand class. }\end{array}$ & Not Supported \\
\hline 4 & Higher fairness perceptions lead to a higher intent to return. & Supported \\
\hline
\end{tabular}


Table 2. ANOVA model

\begin{tabular}{lccccc}
\hline \multicolumn{5}{c}{ ANOVA results } \\
\hline Source & DF & Adjusted sum of squares & Mean square & F & Significance \\
\hline Star & 1 & 4.8 & 4.8 & 0.15 & 0.696 \\
Familiar & 6 & 6450.8 & 1076.1 & 34.41 & 0.000 \\
Information & 1 & 96.3 & 96.3 & 3.08 & 0.080 \\
Star $\times$ Familiar & 6 & 372.4 & 62.1 & 1.99 & 0.065 \\
Star $\times$ Information & 1 & 17.25 & 17.25 & 0.55 & 0.458 \\
Familiar $\times$ Information & 6 & 61.8 & 10.3 & 0.33 & 0.922 \\
Error & 799 & 24841.3 & 31.1 & - & - \\
Total & 814 & 32089.0 & - & - & - \\
\hline
\end{tabular}


Table 3. ANOVA hypothesis results.

\begin{tabular}{lll}
\hline Hypothesis & Description & ANOVA result \\
\hline 1 & $\begin{array}{c}\text { Provision of information will increase the perceived } \\
\text { fairness of revenue management (RM) pricing practices. } \\
\text { Consumers who are more familiar with a RM pricing } \\
\text { practice will view that practice as more fair. }\end{array}$ & Not Supported \\
3 & $\begin{array}{l}\text { Customers of a higher-level brand class will believe that } \\
\text { RM pricing practices are less fair than customers of } \\
\text { lower-level brand classes. }\end{array}$ & Not Supported \\
3a & $\begin{array}{l}\text { Customers who are provided with information about a } \\
\text { RM pricing practice will consider the fairness of those } \\
\text { practices to be the same, regardless of brand class. }\end{array}$ & Not Supported \\
$3 \mathrm{~b}$ & $\begin{array}{l}\text { Customers who are more familiar with RM pricing practices } \\
\text { will consider the fairness of these practices to be the same, }\end{array}$ & Not Supported \\
& regardless of brand class. & \\
\hline
\end{tabular}


Figure 1. Proposed model.

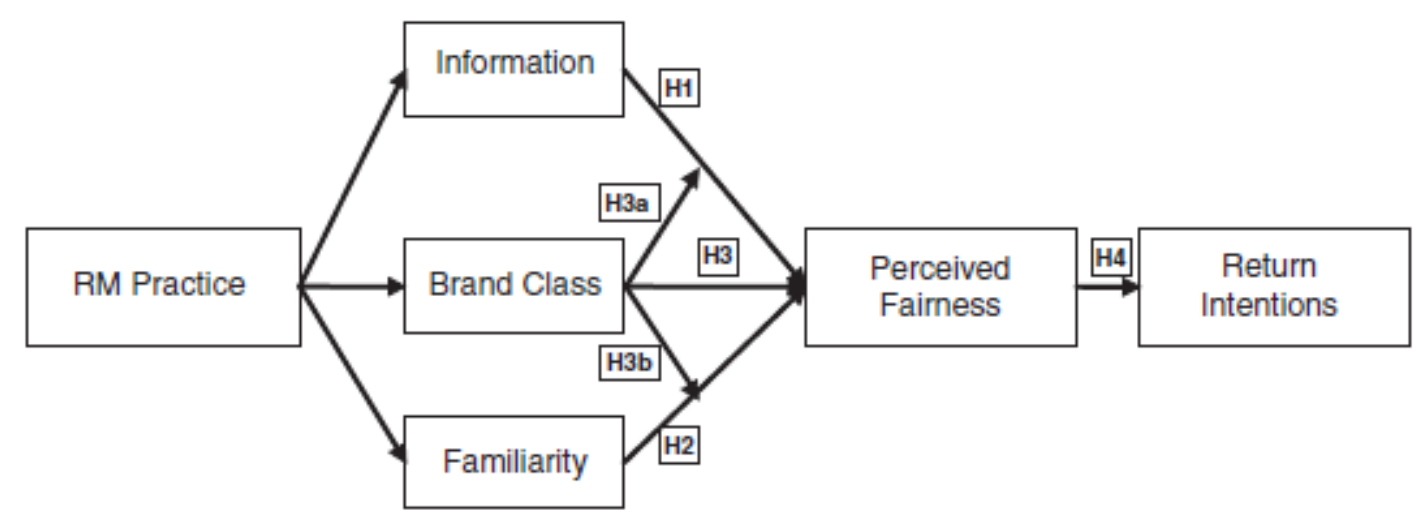




\section{References}

Aaker, D.A. (1996) Building Strong Brands . New York: Free Press.

Aaker, D.A. and Keller, K.L. (1990) Consumer evaluation of brand extension. Journal of Marketing 54 (1): 27-41.

Bolton, L.E., Warlop, L. and Alba, J.W. (2003) Consumer perceptions of price (un)fairness. Journal of Consumer Research 29 (4): 474-491.

Burnsed, B. 2009 Where discounting can be dangerous. Business Week 3 August: 49.

Campbell, M.C. (1999) Perceptions of price unfairness: Antecedents and consequences. Journal of Marketing Research 36 (2): 187-199.

Choi, S. and Mattila, A.S. (2005) Impact of information on customer fairness perceptions of hotel revenue management. Cornell Hotel and Restaurant Administration Quarterly 46 (4): 444-451.

Cook, T.C. and Campbell, D.T. (1979) Quasi-experimentation: Design and Analysis Issues for Field Settings . Chicago, IL: Rand McNally.

Dawar, N. and Parker, P. (1994) Marketing universals: Consumers' use of brand name, price, physical appearance, and retailer reputation as signals of product quality. Journal of Marketing 58 (April): 81-95.

Dodds, W. and Monroe, K. (1985) The effect of brand and price information on subjective product evaluations. Advances in Consumer Research 12 (1): 85-90.

Dodds, W., Monroe, K. and Grewal, D. (1991) The effect of price, brand, and store information on buyers' product evaluations. Journal of Marketing Research 28 (3): 307-319.

Greenberg, J. and Ornstein, S. (1983) High status job title as compensation for underpayment: A test of equity theory. Journal of Applied Psychology 68 (2): 285-297.

Gupta, K. and Stewart, D. (1996) Customer satisfaction and customer behavior: The differential role of brand and category expectation. Marketing Letters 7 (3): 249-263.

Havlena, W.J. and Holbrook, M.B. (1986) The varieties of consumption experience: Comparing two typologies of emotion in consumer behavior. Journal of Consumer Research 13 (3): 394-404. 
Homburg, C., Hoyer, W.D. and Koschate, N. (2005) Customers' reactions to price increases: Do customer satisfaction and perceived motive fairness matter? Journal of the Academy of Marketing Science 33 (1): 36-49.

Kahneman, D., Knetsch, J.L. and Thaler, R. (1986a) Fairness and the assumptions of economics. Journal of Business 59 (4): S285-S300.

Kahneman, D., Knetsch, J.L. and Thaler, R. (1986b) Fairness as a Constraint on Profit Seeki. L., 1993. Conceptualizing, measuring, and managing customer-based brand equity. Journal of Marketing 57 (1): 1-22.

Keller, K.L. (1993) Conceptualizing, measuring, and managing customer-based brand equity. Journal of Marketing 57 (1): 1-22.

Kimes, S.E. (1994) Perceived fairness of yield management. Cornell Hotel and Restaurant Administration Quarterly 35 (1): 21-30.

Kimes, S.E. and Chase, R.B. (1998) The strategic levers of yield management. Journal of Service Research 1 (2): 156-166.

Kimes, S.E. and Noone, B.M. (2002) Perceived fairness of yield management: An update. Cornell Hotel and Restaurant Administration Quarterly 43 (1): 28-29.

Kimes, S.E. and Wirtz, J. (2003) Has revenue management become acceptable? Findings from and international study on the perceived fairness of rate fences. Journal of Service Research 6 (2): 125-135.

Kwun, J.W. and Oh, H. (2004) Effects of brand, price, and risk on customers' value perceptions and behavioral intentions in the restaurant industry. Journal of Hospitality and Leisure Marketing 11 (1): 31-49.

Maxwell, S. (2002) Rule-based price fairness and its effect on willingness to purchase. Journal of Economic Psychology 23 (2): 191-212.

Oliver, R.L. and Swan, J.E. (1989) Equity and disconfirmation perceptions as influences on merchant and product satisfaction. Journal of Consumer Research 16 (3): 372-383.

Rao, A.R. and Monroe, K.B. 1988 The moderating effect of prior knowledge on cue utilization in product evaluations. Journal of Consumer Research $15: 253-264$.

Shapiro, C. (1983) Premiums for high quality products as return to attributes. The Quarterly Journal of Economics 98 (4): 659-679.

Sinha, I. and Batra, R. (1999) The effect of consumer price consciousness on private label purchase. International Journal of Research in Marketing 16 (3): 237-251. 
U.S. Census Bureau. (2007) Age and Sex, http://factfinder.census.gov/servlet/STTable?_bm=y\&-geo_id=01000US\&qr_name=ACS_2007_3YR_G00_S0101\&-ds_name=ACS_2007_3YR_G00_, accessed 1 January 2009, from U.S. Census Bureau.

Volcheff, L. (2009) Consider Discounting in today's economy. Hospitality Upgrade Spring: 22.

Wirtz, J. and Kimes, S. E. (2007) The moderating role of fairness perceptions of revenue management pricing. Journal of Service Research 9 (3): 229-240.

Zeithaml, V. (1988) Consumer perceptions of price, quality, and value: A means end model and synthesis of evidence. Journal of Marketing 52 (July): 2-22. 


\section{APPENDIX}

\section{Exhibit 1: Scenario template and examples}

Below is the template as well as examples of two of the eight scenarios that were provided to respondents. Each respondent received one of the eight scenarios, which was presented at the beginning of the survey.

\section{Template}

You are going out of town on a (Type of trip: 'business' or 'leisure') trip for a couple of days. You will be staying at a hotel (brand class: 'five-star hotel (similar to a Ritz Carlton, St Regis or Four Seasons), which offers amenities such as personalized service, automatic turndown service, 24-hour room service and valet parking' or 'three-star hotel (similar to a Holiday Inn, Courtyard by Marriott or Four Points by Sheraton), which offers amenities such as room service, a fitness center and a full-service restaurant').

(Information: 'When quoted the room rate, the reservation agent explains that the prices for the hotel vary by day of week and how far ahead you book. The rates tend to be higher when booked close to arrival and on certain nights' or ".)

While socializing with other guests at the hotel, you find out that even though they're staying in a similar room, some of them are paying a lot more than you and some are paying a lot less than you.

\section{Example 1: Five-star business trip with information}

You are going out of town on a business trip for a couple of days. You will be staying at a fivestar hotel (similar to a Ritz Carlton, St Regis or Four Seasons), which offers amenities such as personalized service, automatic turndown service, 24-hour room service and valet parking.

When quoted the room rate, the reservation agent explains that the prices for the hotel vary by day of week and how far ahead you book. The rates tend to be higher when booked close to arrival and on certain nights.

While socializing with other guests at the hotel, you find out that even though they are staying in a similar room, some of them are paying a lot more than you and some are paying a lot less than you.

\section{Example 2: Three-star leisure trip with no information}

You are going out of town on a leisure trip for a couple of days. You will be staying at a threestar hotel (similar to a Holiday Inn, Courtyard by Marriott or Four Points by Sheraton), which offers amenities such as room service, a fitness center and a full-service restaurant.

While socializing with other guests at the hotel, you find out that even though they are staying in a similar room, some of them are paying a lot more than you and some are paying a lot less than you. 